\title{
Finesse in Aesthetic Facial Recontouring
}

\author{
Yueh-Bih Tang Chen ${ }^{1}$, Shih-Heng Chen ${ }^{1}$ \\ and Hung-Chi Chen ${ }^{2}$ \\ ${ }^{1}$ National Taiwan University Hospital, Taipei \\ ${ }^{2}$ China Medical University Hospital, Taichung, \\ Taiwan
}

\section{Introduction}

Pursuing excellence in esthetically restoring a facial contour deformity is always a life-long endeavour for plastic surgeons. Significant facial defects, deformity or overt disfigurement, either soft tissue or skeletal or a combination of both, usually bring about aesthetic, functional and of course psychosocial impact. This situation is usually the formidable misery of the head and neck cancer patients with possible significant tissue loss. Strategy regarding the mode of reconstruction in order to obtain the most outstanding result is of utmost importance. Most reconstructions employing microvascular free tissue transfer often emphasize on tissue replacement and functional restoration. Based on 30 years experience in plastic surgery and free tissue transfers, the authors stressed on aesthetic refinement on each patient receiving either conventional methods or free tissue transfer for facial recontouring.

\section{Material}

The disease entity encompasses congenital anomalies, facial tumors (benign or malignant), or radionecrosis resulting in orbital, nasal, maxillary, mandibular or a combination of any of them, with functional defects amounting more than 1000 cases.

\section{Methods}

Minor defects might be reconstructed with various kinds of grafts, or miscellaneous implants. However, free tissue transfers should be selected for major reconstructions, which include groin flaps, radial forearm flaps, scapular flaps, anterolateral thigh flaps, latissimus dorsi, gracilis muscle, vascularized iliac bone, vascularized fibula or scapular bone, etc. Besides the success of the free tissue transfers, applications of various fundamental skills in plastic surgery will upgrade the result of the reconstruction to a higher hierarchy, which include Z-plasties, W-plasty, fat grafting, cartilage grafting, full-thickness skin grafting, specially designed sling surgery or even craniofacial skills--calvarial bone grafting, bilateral sagittal split osteotomy, sliding genioplasty, etc. Details of finesse in aesthetic facial 
recontouring using miscellaneous basic plastic surgery principles or microvascular free tissue transfers will be presented and discussed in the following selected representative cases.

As a plastic surgeon, pursuing excellence is always the gold standard. This involves technical mastery, enhancing experience, redeeming morality, development of accountability, eliciting ideas \& innovations, emphasizing on humane solicitude, enriching artistic sense in order to get to the goal of pursuing excellence.

\section{Considerations on facial recontouring}

The basic fundamental principle of engaging in facial recontouring for the head and neck cancer patients is to aim at anatomical restoration as long as possible at the very beginning. If it's impossible, then tissue transfer with any measure should be employedshould it be a local flap, axial pattern flap, island flap or free tissue flap with any kind of tissue combinations. Certain percent of facial recontouring only requires volume reduction or volume replacement. Some patients with skeletal derangements need skeletal rearrangement-be it an osteotomy/ osteotomies with or without bone grafting or implant placement. Of course, proper anchorage of the facial interface is another important issue.

In patients with vascular malformations, skin problems should also be solved with intravascular embolization in collaboration with subtle use of appropriate selection of lasers in addition to sclerotherapy. Motor function disturbance at the face ( facial paralysis or paresis) is another frequently encountered problem at the face, especially after trauma or tumor extirpation/ radical operation for malignant diseases. The facial expression/ symmetry should be deliberately restored with nerve transfers/ static sling operations/ regional functional muscle transfers/ free functional muscle transfers or combinations of any of the methods. The facial contours, not to mention, should be deliberately redefined and properly highlighted in order to get to a satisfactory result.

- Anatomy - restoration

- Volume - reduction, replacement

- Skeleton - rearrangement

- Interface - proper anchorage

- Skin - refinement, rejuvenation

- Motor Function - recreation; rehab.

- Contour - redefined, properly highlighted

Integration of craniofacial surgery, microsurgery and basic general plastic surgery principles is always indispensible in order to get to an esthetically satisfactory result.

Reconstruction may involve upper face, middle face, or lower face or combinations of any of them. It may also involve single layer reconstruction, double layers reconstruction, or triple layers reconstruction ( sandwich reconstruction). Reconstruction can usually be finished in one operation by choosing the donor site with the least deformity and functional morbidity, and at the same time obtain the most benefit of the patient. 


\section{Table - Methods of facial recontouring}

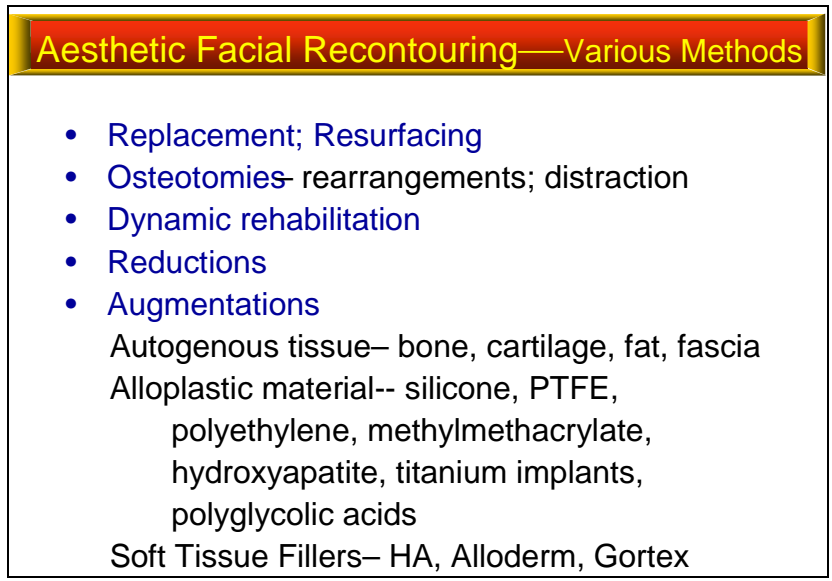

\section{Representative facial derangements}

To esthetically recontour a face has been our main goal in daily encounters, here we select several interesting topics and representative instances to demonstrate the aforementioned methods used in treating facial derangements or enhancing facial esthetics.

6.1 The Fate of Different Reconstructive Modes for Mandibular Ameloblastomas.

6.2 Strategy of Reconstructing Combined Mandibular Defect and Facial Palsy.

6.3 Strategic Approaches to Revisions of Microvascular Oromandibular Reconstructions.

6.4 Upper Facial Recontouring after Facial Tumor Ablation.

6.5 Osteoradionecrosis of the mandible

\subsection{The fate of different reconstructive modes for mandibular ameloblastomas}

Mandibular ameloblastomas are not infrequently seen. However, most of the patients were primarily treated by oral surgeons, ENT surgeons or surgeons who were not comfortable with vascularized bone transfers. Therefore, many patients were left with formidable complications as malocclusion, deviation of chin, facial deformity, chronic intraoral/ extraoral drainage, extrusion and infection of dead bone, soft tissue wasting or even ultimate extrusion of the implant. 


\section{Material and methods}

In 15 years, 57 patients were referred to us for management of the aforementioned problems, only 9 patients with mandibular ameloblastoma were treated primarily by the plastic surgeons. In 57 patients, 21 were reconstructed with nonvascularized bone, 10 of them were complicated with chronic drainage, and 11 of them were complicated with remarkable facial deformity. Thirty six out of the 57 patients were reconstructed with reconstruction plate without incorporation of bone. Ten patients were referred for progressive soft tissue wasting, 32 were referred for overt facial deformity, and 15 of them were referred for extrusion of the implant. The 9 patients treated primarily by the plastic surgeons all obtained satisfactory long term result.

The complicated cases were then reconstructed with vascularized iliac bone in 44 patients, vascularized fibula in 13 patients. The presenting symptoms were deformation and loosening of plates, soft tissue wasting, ended up with chronic drainage and ultimately extrusion of the plates.

\subsubsection{Problems and difficulties of reconstructions with implant failures}

1) Scarring and capsule formation around implants. 2) Difficulty in dissecting and approaching the glenoid fossa. 3) Lack of a clear plane to expand the pocket to accommodate a vascularized bone camouflaged ascending ramus. 4) Possibility of facial nerve injury or traction during dissection or expansion. 5) Placement of incision should be carefully designed since there had been soft tissue atrophy and thinning of skin.

Secondary mandibular reconstruction after implant failure may cause facial nerve injury or difficulty in approaching the glenoid fossa. Fascia lata sling operation is always required in hemimandibular reconstruction in patients with implant failures. Use of mandibular implants as a reconstruction tool should be limited. It is advised that vascularized bone is always the material of choice in major mandibular reconstructions.

\subsection{Strategy of reconstructing combined mandibular defect and facial palsy}

Either a significant mandibular bone defect or facial palsy presents a challenge to plastic surgeons. When these two conditions are present at the same time, the situation becomes even more complicated. The sequence of reconstruction should be thoroughly contemplated. The scars following a free osteocutaneous flap reconstructed mandibular defect will hamper further exploration of facial nerve lesion and vice versa. Here we report 5 patients with combined mandibular defects and facial palsy. The first case was a 28 -year-old woman with an osteogenic sarcoma at left mandibular ramus. She underwent tumor resection, which was complicated with left complete facial palsy. Besides, left hemimandibulectomy was performed for osteoradionecrosis of the mandible as a complication of post-operative irradiation. The severely deformed face lasted for 6 years before she was referred for further reconstruction. An iliac osteocutaneous free flap was used for her mandibular defect followed by a temporalis muscle transfer in order to correct the deviated face. The second case was a 19-year-old young man who suffered from crush injury of the face resulting in right mandibular defect and right facial palsy. The patient received a fibular osteocutaneous 
free flap reconstruction and cross facial nerve grafting simultaneously. The 3rd patient was a lady with malignant parotid tumor, status post-tumor resection with subsequent radiotherapy. She was complicated with osteoradionecrosis of the mandible. Then, hemimandibulectomy and reconstruction with a plate was done by an oral surgeon which resulted in extrusion of the implant and significant facial deformity. The plate was removed and reconstructed with a vascularized scapular flap for the mandible and fascia sling operation for facial palsy. The last 2 cases were victims of oral cancer. Mandibular defect and lower facial palsy resulted after radical surgery. The bony defects were reconstructed with vascularized iliac bone and the lower facial palsy was reconstructed with masseter transfer and contralateral lower lip depressor myectomy. All the 5 patients demonstrated satisfactory functional and aesthetic results.

When mandibular reconstruction and facial nerve operations were carried out separately, it will be difficult to dissect out the facial nerve after mandibular reconstruction, and vice versa. For long-standing facial palsy as in the first case, static muscle transfer provides an alternative. There leaves much to be discussed about the reconstruction for patients with combined mandibular defect and facial palsy.

\subsection{Strategic approaches to revisions of microvascular oromandibular reconstructions}

Free tissue transfers have been employed for reconstructing oro-maxillo-mandibular defects in the past 30 years in our hands, amounting several thousands of patients.

Reconstruction of major oro-maxillo-mandibular defects employing microvascular free tissue transfers are always time-consuming task. In order to quarantee the survival of the flap, certain degree of swelling or tissue excess is usually inevitable. However, excellent result can always be obtained by virtue of proper selection of transferred tissue flap and post-operative refinement based on the basic plastic surgical and maxillofacial surgical principles. However, revisions are always the rule in order to reach an optimal result. The problems encountered can be summarized as:

\subsubsection{Scar contractures - intra-oral/ extra-oral trapdoor scar contractures}

Scar contracture at the oro-maxillo-facial area is inevitable in most of the reconstructed face. Mild forms may be released with Z-plasties, or W-plasty. Moderate contractures may be released with the addition of full-thickness skin grafts. Severe contractures should employ local flap or partial skin flap transposition with preformed free tissue flap ( Revolving Door Switch-over Flap Technique).

\subsubsection{Facial palsies - partial/ total}

Complete facial palsy or paresis of branches of the facial nerve may be left with orofacial surgeries. For complete facial palsies, immediate bridging nerve grafting / hypoglossal nerve grafting/ cross facial nerve grafting can achieve satisfactory results. For facial paresis with incomplete recovery, cross facial nerve grafting with proper neurotization can significantly augment the facial reanimation. For weakness of the depressor anguli oris/ 
depressor labii inferioris, chemical denervation of the contralateral counterpart with botulinum toxin A can alleviate the asymmetry of the lower lip expressions.

\subsubsection{Oral incompetence causing drooling}

Oral incompetence often occurs after lip cancer/ buccal cancer/ gingival cancer operations. Therefore, it's advised that preservation of part of the orbicularis oris muscle and proper anatomical restoration is of utmost importance during tumor surgery, otherwise drooling will become a formidable and an unwelcome morbidity.

\subsubsection{Loss of skeletal support}

In mandibular tumors which resulted in insufficient skeletal height or even segmental bony defect, oral incompetence may also be noticeable with frequent sucking behavior during speaking.

\subsubsection{Skin color mismatch}

Partial skin resection and reconstruction at the face may result in skin color mismatch with possible trapdoor deformity, which necessitates further disposal.

\subsubsection{Mandibular implant extrusions}

Many of the mandibular reconstructions were done by ENT or dental-oral surgeons with bridging implant only without bony reconstruction or with conventional bone graft which ultimately resolved. In the long run, not only the implant extruded, but also the neighboring soft tissue would significantly shrink after daily friction which deemed to wasting with periimplant capsular contracture.

\subsubsection{Facial asymmetry / disfigurement}

Facial asymmetry with different degree may be recontoured with addition of volume with fat grafting or injection with soft tissue fillers in order to minimize facial disfigurement.

Based on the experiences of doing more than 1500 oro-maxillo-mandibular reconstructions in our plastic surgery groups, we present our strategies in pursuing good results for our patients. There are a lot of amendment procedures to be carried out aiming at achieving not only functional recovery, but also aesthetic restoration. The procedures are as follows:

1. Release of trismus, deepening of buccogingival sulcus.

2. Debulking, $\mathrm{Z}$ plasties or $\mathrm{W}$-plasty to alleviate trapdoor scarring.

3. Muscle transfers or tendon sling operation for facial palsies.

4. Skeletal recontouring.

5. Restoring oral competence/ oral commissuroplasty.

6. Fat grafting or using soft tissue fillers

7. Botulinum toxin A injection for dynamic asymmetry

With deliberate planning and proficient skills, optimal results can always be achieved ultimately. Details in dealing with miscellaneous problems in several representative patients will be presented and thoroughly discussed. 


\section{Case presentations}

Case 1. Reconstruction for secondary mandibular deformity

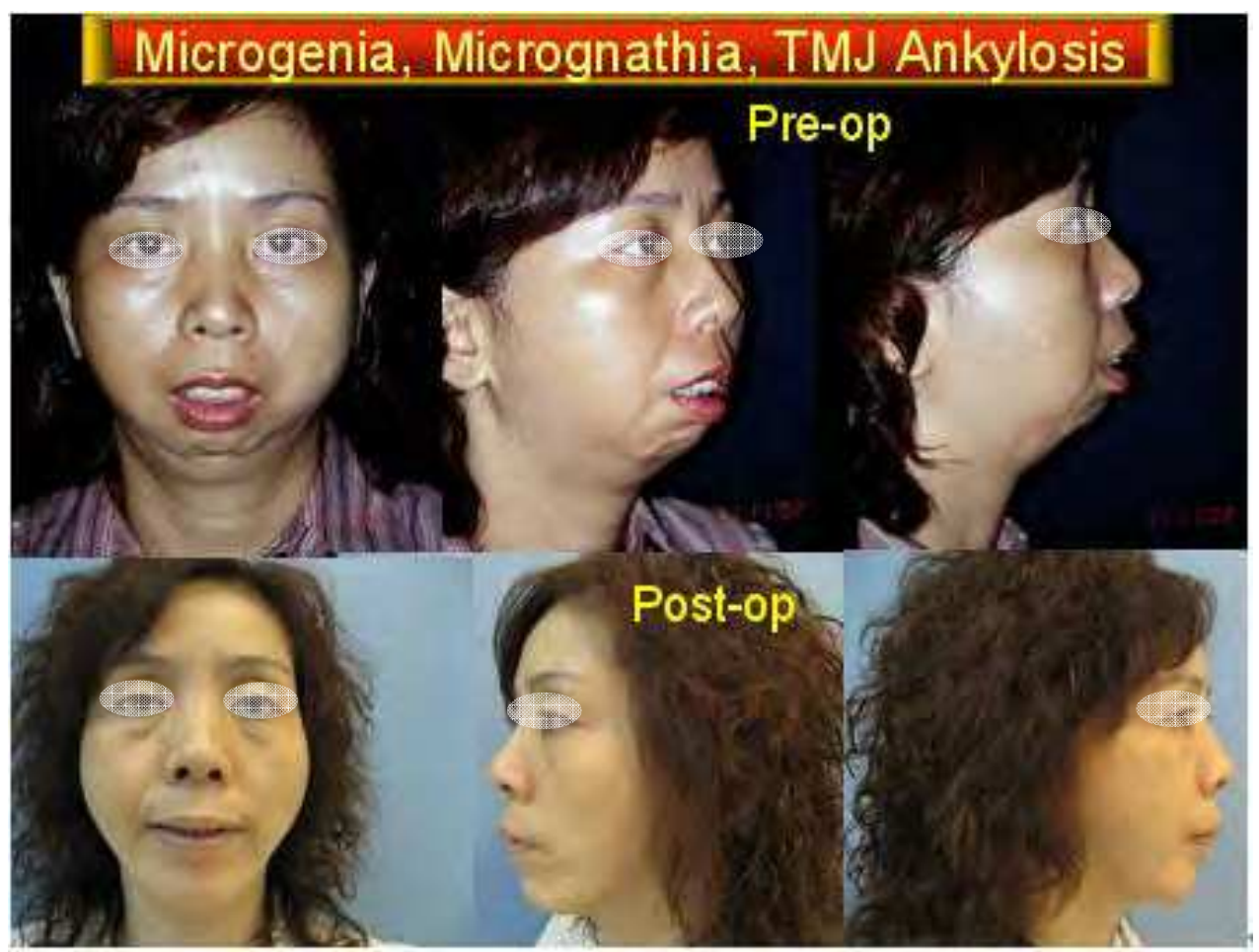

Fig. 1. Microgenia, Micrognathia, TMJ Ankylosis. This 42 year-old lady became microgenic and micrognathic with oral incompetence since she was very young due to some kind of ailment that she can not remember very well. She always shun herself from the public for not having a chin. Orthognathic surgery with bilateral sagittal split osteotomy, sliding genioplasty and Medpor chin implant placement were carried out after orthodontic treatment. She has been very satisfied with the operation. 
Case 2. Reconstruction of combined major mandibular deficiency and facial palsy

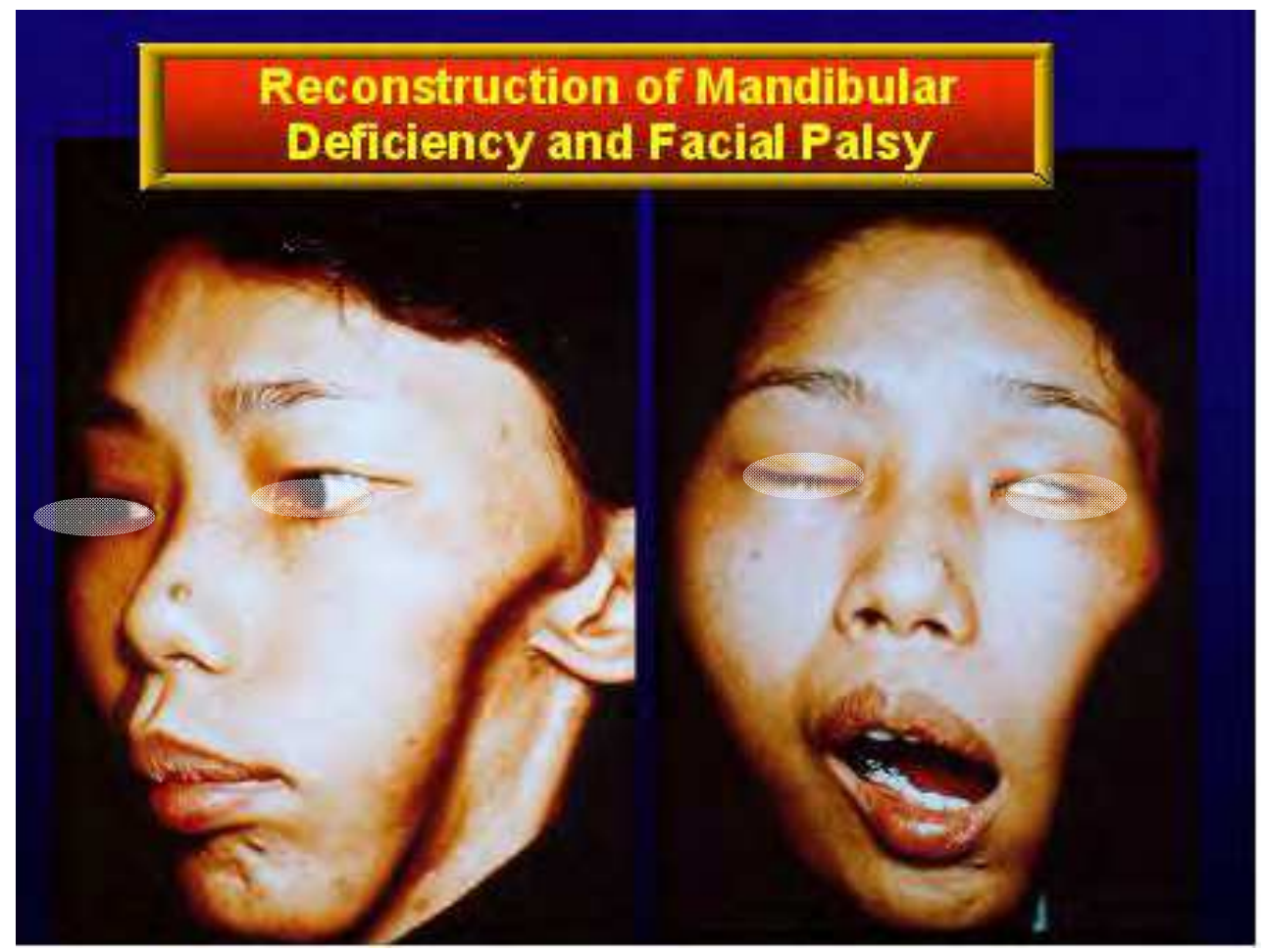

Combined Mandibular Deficiency and Facial Palsy. This 28 year-old lady suffered from osteogenic sarcoma at the left mandibular ramus at the age of 18 .

Fig. 2.1. Reconstruction of Mandibular Deficiency and Facial Palsy. 


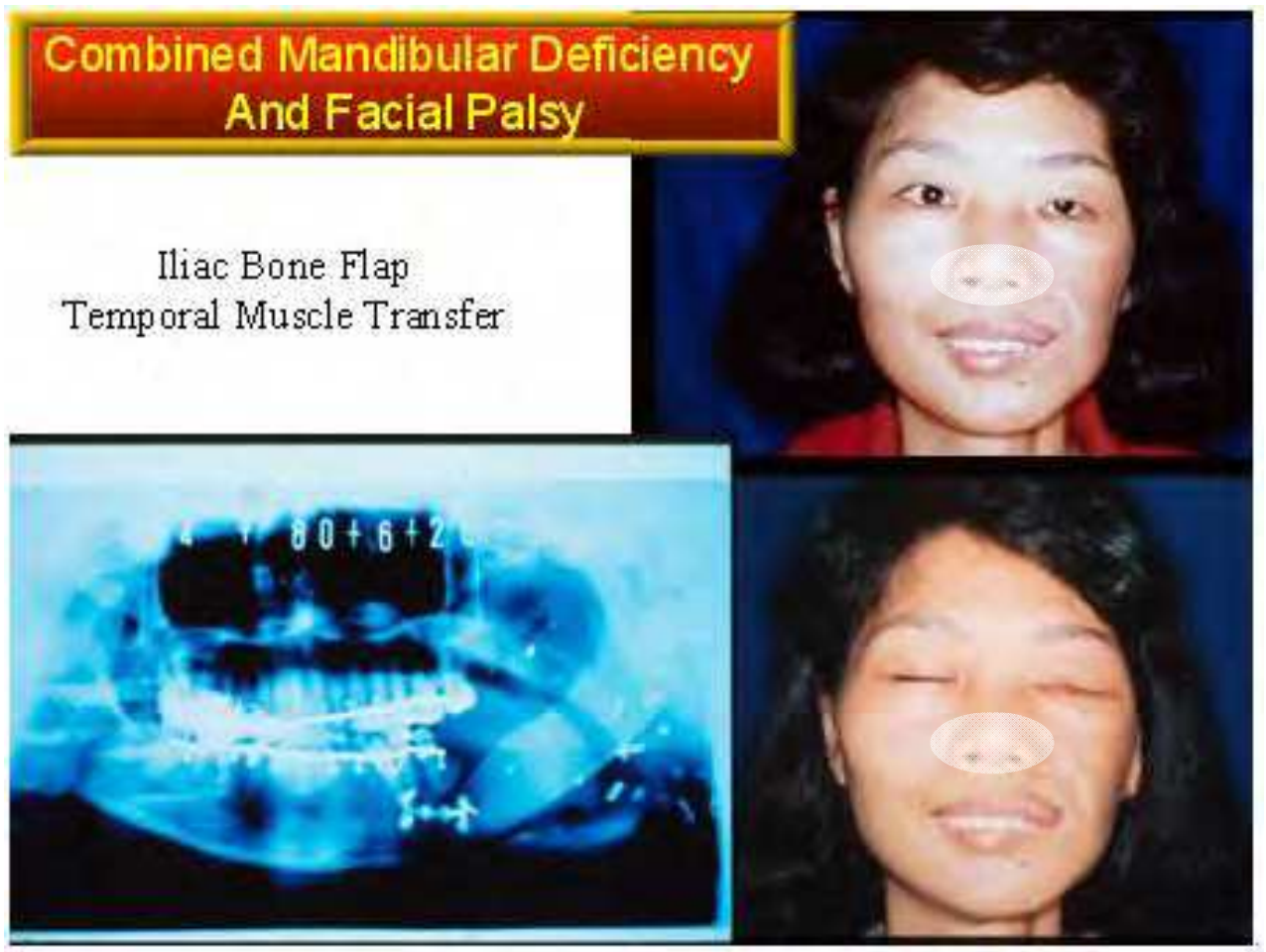

Fig. 2.2. Post-op. Combined Mandibular Deficiency and Facial Palsy. She received tumor excision by an ENT surgeon, and then was told to receive radiotherapy. She was then complicated with left facial palsy and osteoradionecrosis of the mandible and resulting in hemimandibulectomy. Since then, she suffered from a severely deformed face. Under her request, we reconstructed her left mandible with vascularized iliac bone flap which restored not only the hemimandibular defect but also soft tissue deficiency after previous extremely destructive surgery. After 6 months, we used left side temporalis muscle transfer and partial masseter muscle transfer to balance her left side face with that of the right side and also to treat left lagophthalmos. 


\section{Case 3. Reconstruction of upper facial deformity}

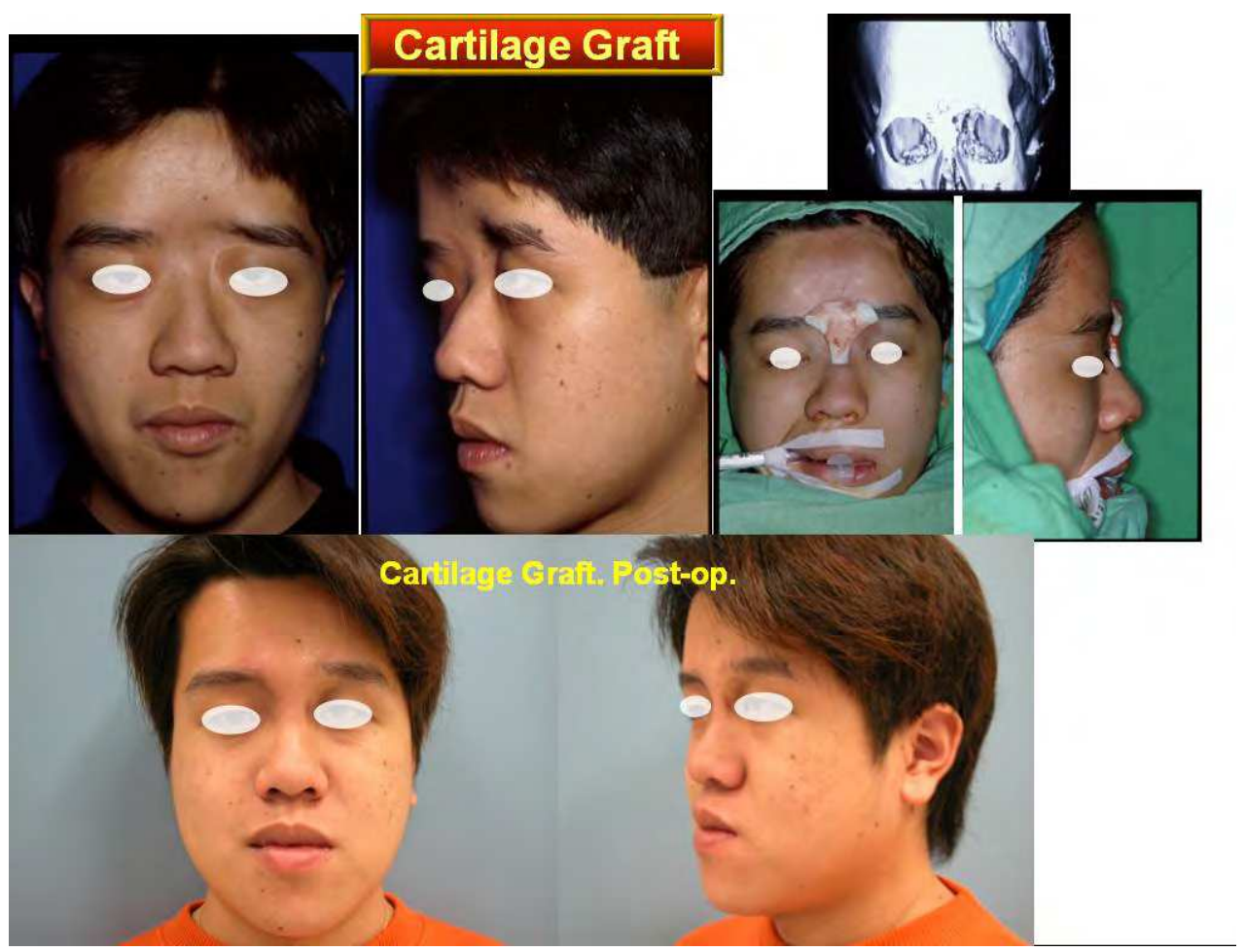

Fig. 3. Fronto-naso-orbital Defect

This 18 year-old boy was found to have a tumor at the left fronto-naso-orbital area when he was 6 year-old. Pathology after excision revealed an eiosinophilic granuloma, he then received chemotherapy afterwards. As he grew up, hypoplasia of the fronto-naso-orbital complex bothered him greatly. In order to recontour this area, we harvested a costal cartilage block which was carved to match the 3 dimensional configuration of the defect, and then wrapped with fascia graft, to be inserted into the defect through an incision at the frontal scalp. He then got a satisfactory facial contour. 


\section{Case 4. Reconstruction of mandibular implant extrusion}

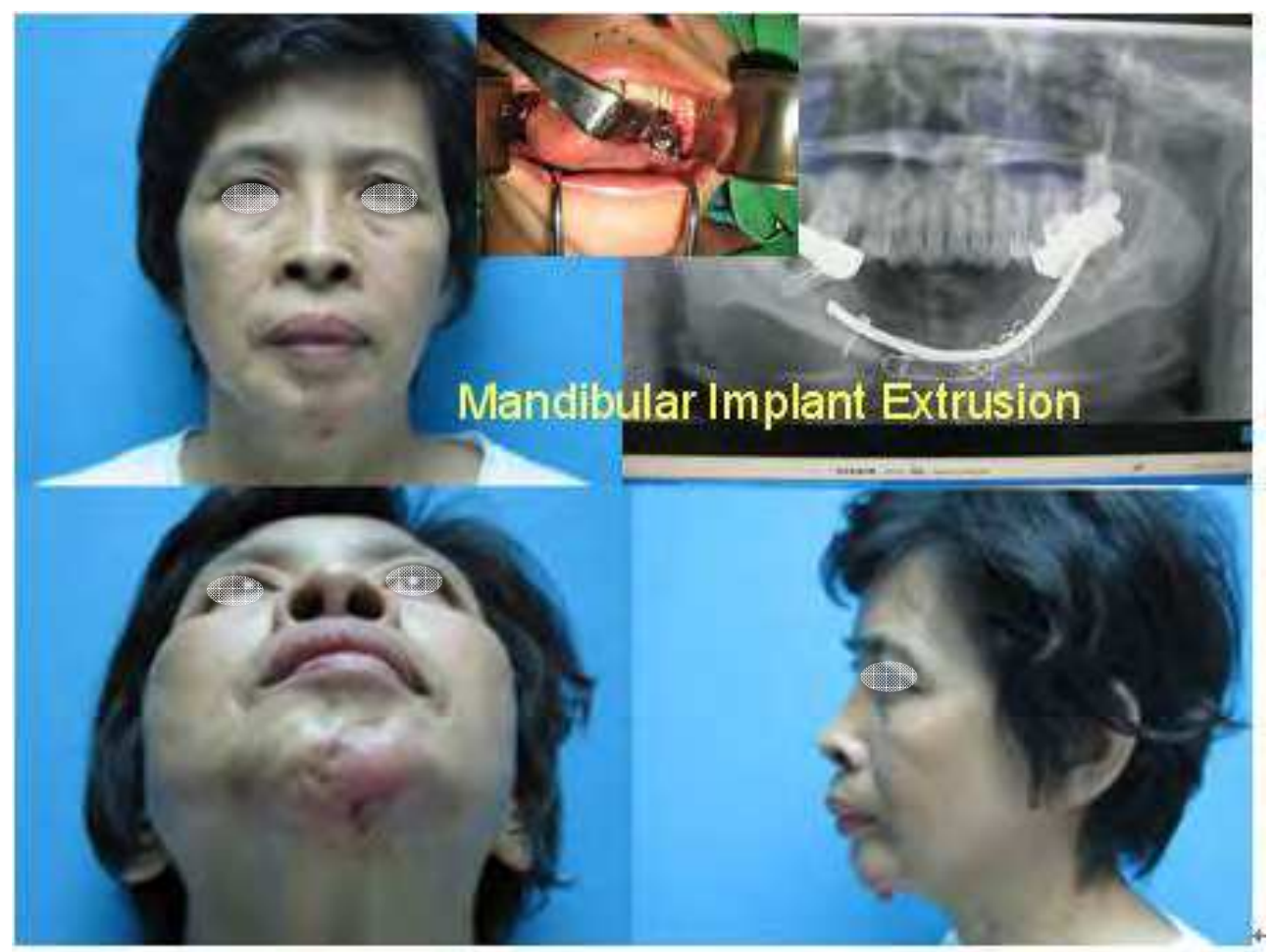

Fig. 4.1. Pre-op. This 56 year-old lady suffered from ameloblastoma of the mandibular symphysis 10 years previously. She received segmental mandibulectomy by an dental surgeon, and at the same time was reconstructed with a curved metallic implant. Several years later, she started to notice deformity of the chin, and then furtherly complicated with chronic drainage from the bottom of the chin with pointing out of the sharp tip of the implant piercing out the left side lower vestibular sulcus mucosa. 

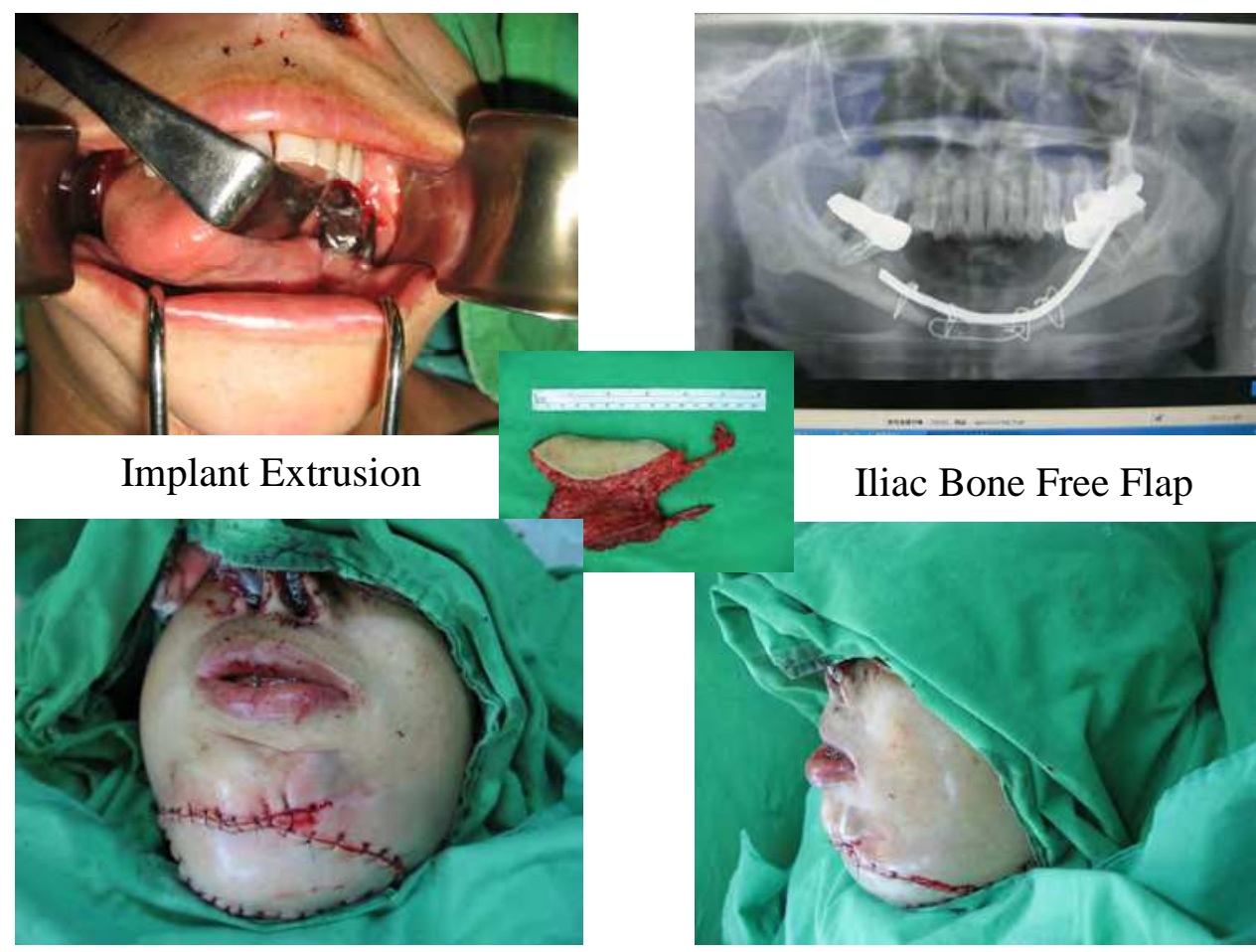

Iliac Bone Free Flap

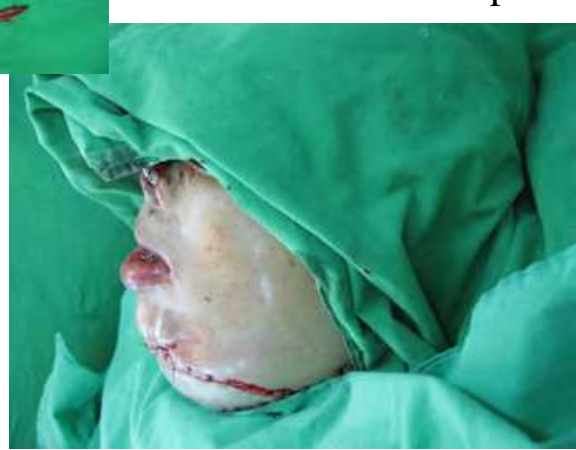

Fig. 4.2. At the first operation, the extruded and infected implant was removed and the wound was debrided thoroughly and the defect of the mandibular symphysis, skin and soft tissue was reconstructed with a vascularized iliac bone flap with complete success. 


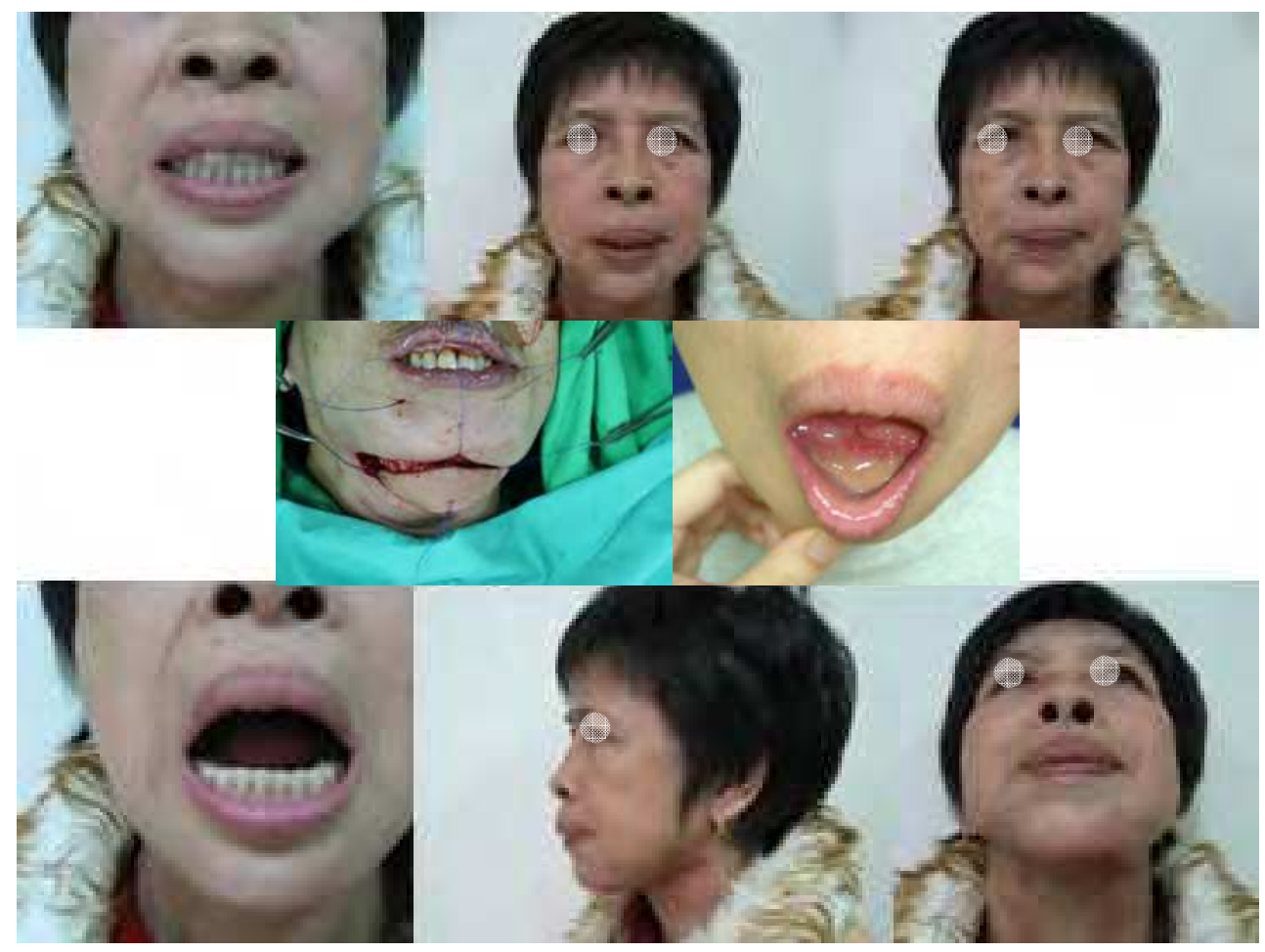

Fig. 4.3. Post-op. After 6 months, bone union had been secured and swelling of the reconstructed skin and soft $\mathrm{t}$ tissue bulk had subsided, the excess skin flap at the chin was used to deepen the insufficient lower sulcus by using the revolving door switch-over technique. In addition to deepen the sulcus to better accommodate dental implant placement, this measure also provided ample soft tissue for chin augmentation. 


\section{Case 5. Immediate anatomical restoration for mandibular ameloblastoma}

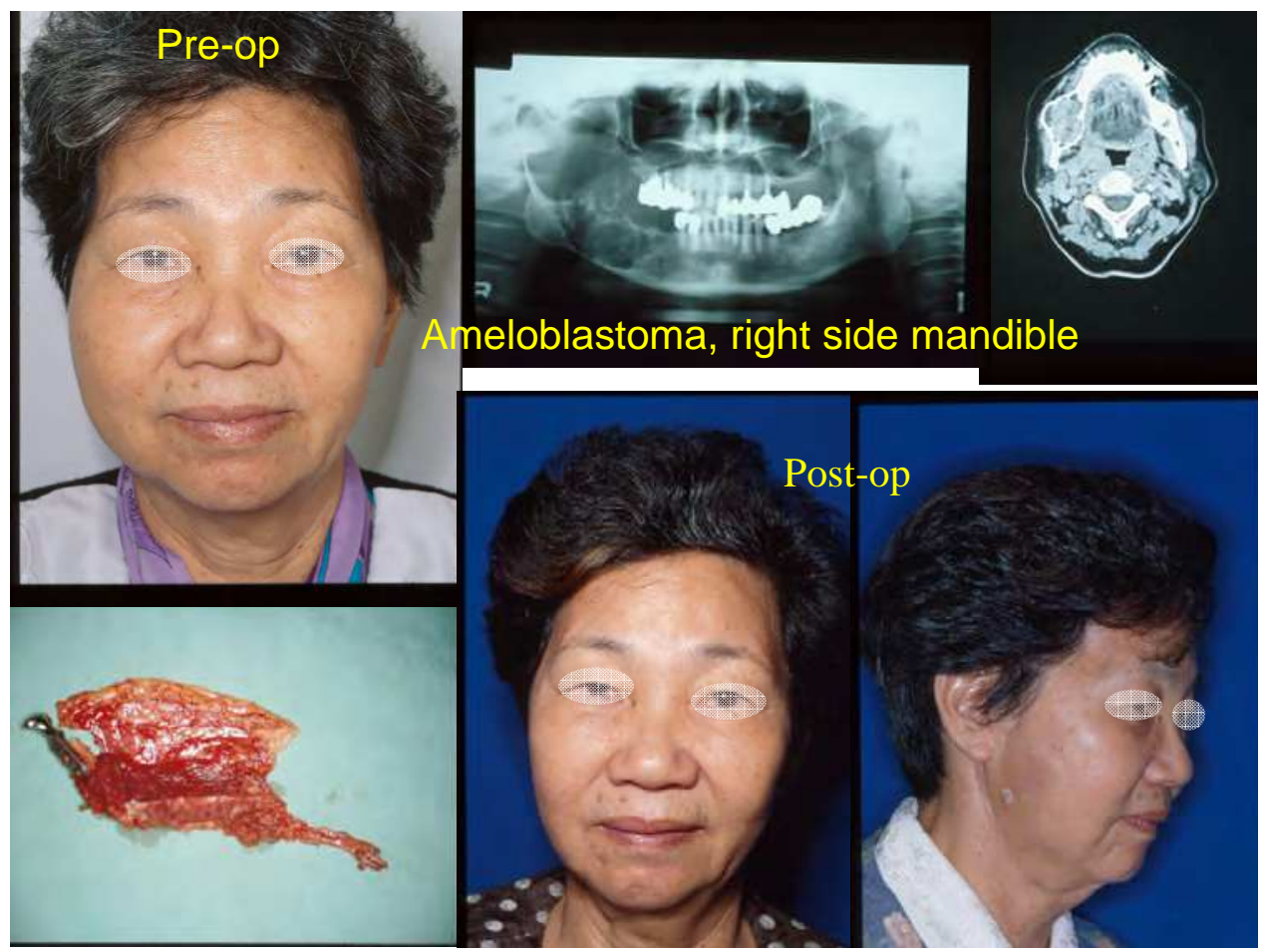

Fig. 5. This 63 year-old lady started to notice that she cannot open her mouth freely, and finally was found that she had a giant ameloblastoma at her right side mandibular body, extending to right mandibular ramus, condyle and coronoid process. She can hardly open her mouth as the tumor grew bigger and bigger. The tumor was resected en bloc, and at the same time replaced with a fibular osteocutaneous flap incorporating with a piece of titanium condyle to reconstruct her right side mandible and buccogingical lining. After 6 months, she received autogenous fat injection to further augment her right cheek for better facial contour and symmetry. 


\section{Case 6. Osteoradionecrosis of the mandible}

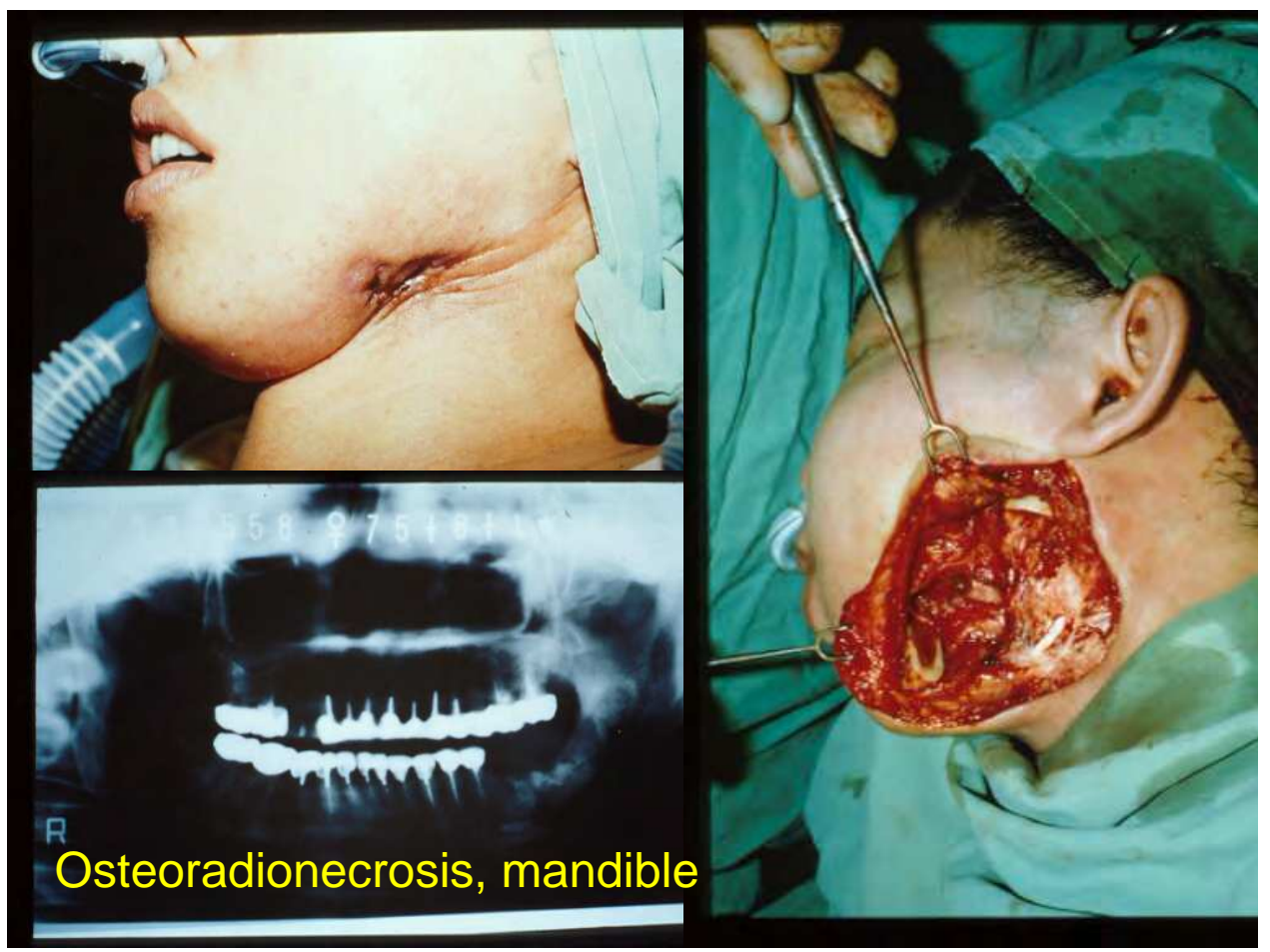

Fig. 6.1. This 42 year-old lady contracted a left submandibular tumor when she was 24 yearold. After resection, the pathology report revealed a mucoepidermoid carcinoma of the submandibular gland. She was arranged to receive radiotherapy. Eighteen years after the treatment, she suffered from left lower jaw teeth pain. Ever since teeth extraction by the dentist, the wound never healed and furthermore complicated with foul odor discharge from left side mandible, despite of 80 treatments of hyperbaric oxygen. Besides, she also suffered from intractable pain. Therefore, the osteonecrotic mandible was resected and the wound debrided thoroughly. 


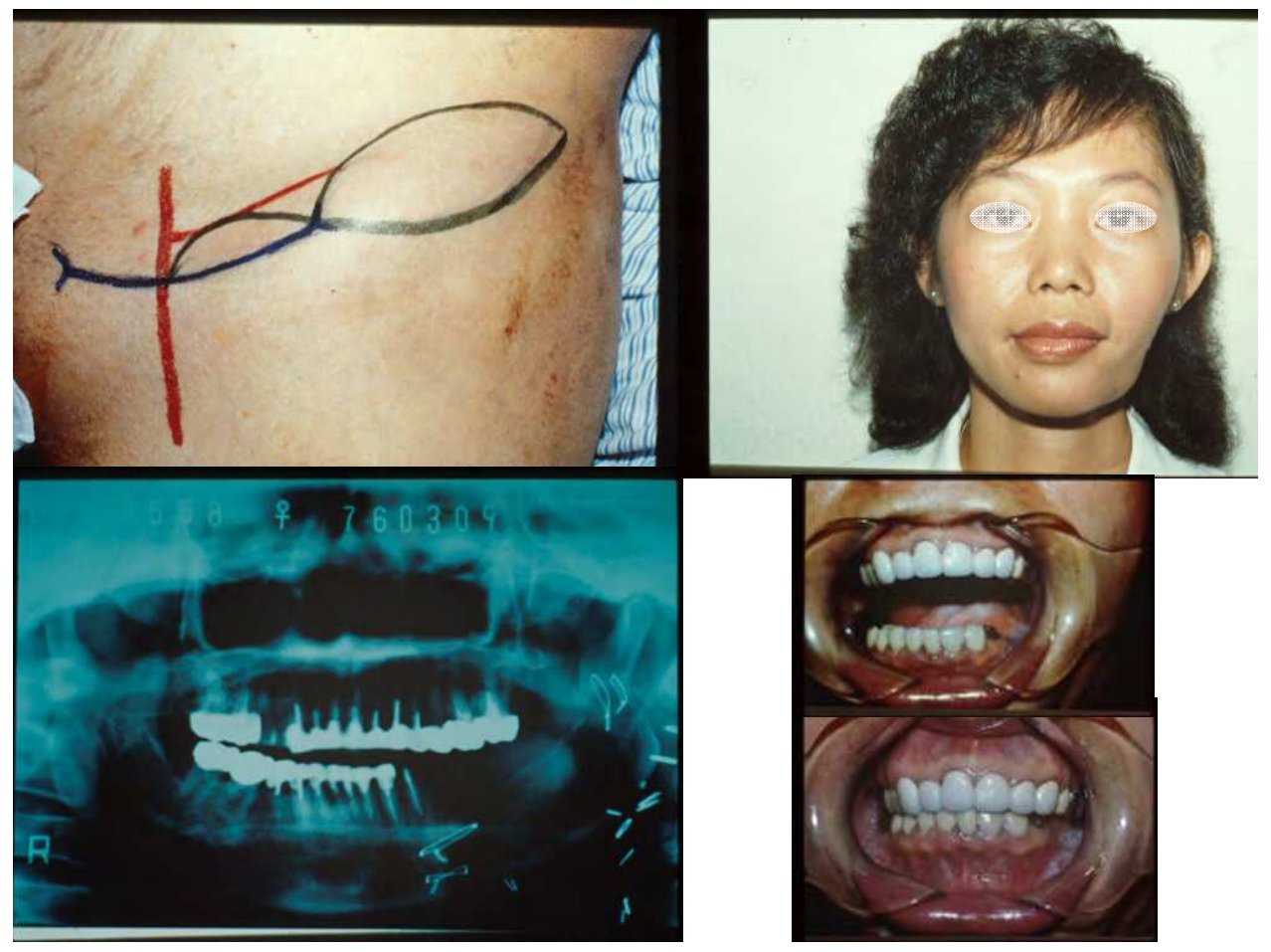

Fig. 6.2. The defect was reconstructed with a piece of vascularized iliac bone flap harvested from ipsilateral side with complete success. Besides maintaining satisfactory facial contour and symmetricity, the patient assumed good occlusion and can open her mouth freely without trismus. 


\section{Case 7. Reconstruction of secondary facial deformity}

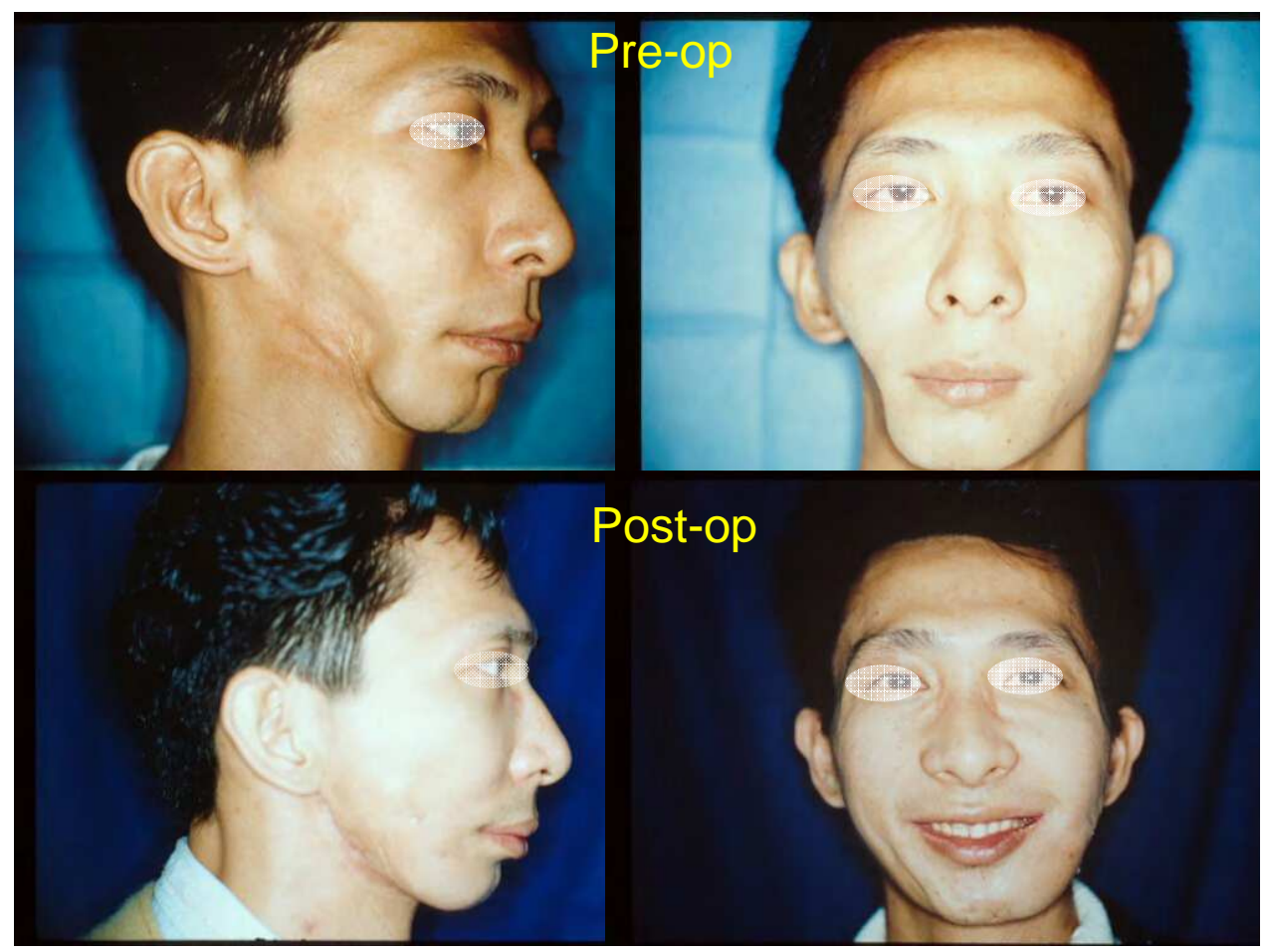

Fig. 7. This 25 year-old young man received resection of right side mandible by dental surgeons for ameloblastoma. He was left with a sunken cheek and deformed face, and became autistic and reluctant to go out. We reconstructed his right side mandible with a fibular osteocutaneous flap with 2 osteotomies and incorporating with a titanium mandibular condyle. After the operation, he regained facial symmetricity and normal facial contour, therefore resumed his bright smile again. 


\section{Conclusions}

There are miscellaneous methods aiming at recontouring of the face for different purposes. Anatomical restoration is always the rule of thumb to achieve satisfactory aesthetic result. Overall, a comprehensive approach with integration of craniofacial surgery, microsurgery, aesthetic surgery and basic plastic surgical techniques will get to most outstanding results.

\section{Acknowledgement}

Reconstructions of facial derangements are usually time-consuming, and sometimes multistage tasks. Team approach is always a must. Here we would like to express our sincere thanks to whom ever joined the tedious works described in this text. Without their help, the difficult reconstructions can not be accomplished. The authors also have to give thanks to Mavis Kuo for her proficiency in editing this chapter.

\section{References}

Chao-Hsiang Lee, Ming Ting Chen, Yueh-Bih Tang*. (2008) Reappraisal of Using Platysma Myocutaneous Flap for Lower Facial Reconstruction. The Journal of Plastic surgical Association. ROC. Vol. 17, No.1, p.24-34.

Chen, CK. \& Tang, YB. (2009). Myectomy and botulinum toxin for paralysis of the marginal mandibular branch of the facial nerve: a series of 76 cases. Plast Reconstr Surg. 2007 Dec; 120(7): 1859-64 SCI (27/167) Surgery. 2009

Chen, NC.; Tai, HC. ; Chien, HF. \& Tang, YB. (2002) Ancillary Procedures in Refining Microvascular Oromandibular Reconstructions. Proceedings of $18^{\text {th }}$ Annual meeting of Taiwan Surgical Association. (2002/ 3/23-24). P173

Cheng NC, Ko JY, Tai HC, Horng SY, Tang YB*. (2008) Microvascular head and neck reconstruction in patients with liver cirrhosis. Head Neck. Vol.30, No.7, p.829-35.

Cheng, NC. ; Chen, MT. ; Tang, YB. \& Tai, HC. (2005). Immediate Free Flap Reconstruction in the Management of Advanced Mandibular Osteoradionecrosis. The Journal of Plastic surgical Association. ROC. 2005 Vol. 14, No. 2, p.121-130.

Cheng, NC. ; Hsie, RH. ; Tai, HC. \& Tang, YB. (2004). Ancillary Procedures for Refining Major Oromandibular Reconstructions. Proceedings of 19th Annual meeting of Taiwan Surgical Association. (2004 /3/27-28) P231

Colenan, JJ. \& Woden, WA. (1990). Mandibular reconstruction with composite microvascular tissue transfer. Am J Surg 1990; 160 :390-5.

Hidalgo, DA. (1989). Fibula free flap: a new method of mandible reconstruction. Plast Reconstr Surg $1989 ; 84: 71-9$.

Hsieh, MH. ; Huang, CM. ; Peng, SF. ; Chen, CM. ; Wong, JM. \& Tang, YB. (2003). Using Image Segmentation Technique in the Treatment of Craniofacial Soft Tissue Neoplasm. Proceedings of $18^{\text {th }}$ Annual meeting of Taiwan Surgical Association. (2003/ 3/29-30). P220

Hung-Chi Chen, Ming-huei Cheng, Yueh-Bih Tang. (2003) Head and Neck Reconstruction in Trauma and Cancer. Seminars in Plastic Surgery, Vol. 17, No.1, p.23-37. 
Hung-chi Chen, Yueh-bih Tang, Kuo-Lian Tseng. (2001) The Anatomical Variations of Posterior Interosseous Artery. Congress of the International Societies of the Hand (IFSSH) Turkey, Istanbul. (6/10-14) p.239-40.

Hung-chi Chen, Yueh-bih Tang, Kuo-Lian Tseng. (2001) Treatment for Avascular Necrosis of Scaphoid With Microvascular Free Cortico-periosteal Flap. Congress of the International Societies of the Hand (IFSSH). Turkey, Istanbul. (6/10-14 ) p.594-6.

Lei-Ming Sun, Han-Ming Tsung, Yuh-Yuan Shian, Shyh-Jye Chen, Ching-Shiow Tzeng, Yueh-Bih Tang *. (2002) Computer- Generated Simulation Template for FrontoNaso- Orbtal Reconstruction. Formosan Journal of Surgery. Vol.35, No. 1. p.28-33.

Mark, RJ. ; Sercarz, JA. \& Tran, L. et al (1991). Osteogenic sarcoma of the head and neck. The UCLA experience. Arch Otolaryngol Head Neck Surg 1991;117 :761-6.

Mon-Hsian Hsieh*, Shing-Guang Lai, Yueh-Bih Tang. (2005) Correction of the Webbed Neck Deformity in Noonan Syndrome. The Journal of Plastic surgical Association. ROC. Vol. 14, No. 4, p355-362.

Nai-Chen Cheng, M.D., Dar-Ming Lai, M.D., Mon-Hsian Hsie, M.D., Shu-Lang Liao, M.D., and Yueh-Bih Tang Chen*, M.D., Ph.D.(2006) Intraosseous Hemangiomas of the Facial Bone. Plastic and Reconstructive Surgery. Vol.117, No.7, p.2366-72.

Nai-Chen Cheng, Shyue-Yih Horng*, Shan-Chwen Chang, and Yueh-Bih Tang.(2004) Nosocomial Infection of Aeromonas Hydrophila Presenting as Necrotizing Fasciitis. J Formos Med Assoc. Vol.103, p.53-7.

Tang Chen, YB. (1999). Salvage mandibular Reconstructions after Implant Failures. Proceedings of $13^{\text {th }}$ Symposium of the International Society of Reconstructive Microsurgery, (6/22-25) Los Angeles, USA.

Tang Chen, YB.\& Chen, HC. (1995). Finesse in Microvascular Oromandibular Reconstruction. Proceedings of Plastic, Reconstructive and Aesthetic Surgery. p.531 San Francisco, USA.

Tang Chen, YB.; Lai, SG. ; Chen, HC. (2003). Reconstruction of Combined Mandibular Defect and Facial Plasy. Proceedings of the 8th Confederation of the International Society of Plastic, Reconstructive and Aesthetic Surgery. Aug. Sydney, Australia.

Tang YB. \& Hahn LJ. (1990). Major Mandibular Reconstruction with Vascularized Bone Graft. J Formosan Med Assoc, vol.89, No.1, p.34-40

Tang, YB. (1993). Long Term Survival of Mandibular Osteosarcoma. British Journal of Plastic Surgery. 1999; Apr; Vol.52, No.3, p.243-4

Tang, YB. (1997) Esthetic Considerations after Major Mandibular Reconstruction. The 90th Taiwan Medical Academic Lecture of Formosan Medical Association.( 11/10 ) Taipei, Taiwan.

Tang, YB. (2008). Strategic Approaches to Revisions of Microvascular Oromandibular Reconstructions. Proceedings of American Society for Reconstructive Microsurgery 2008 Annual Meeting. Beverly Hills, USA.

Tang, YB. (2009). Long-term Outcome of Reconstructions for Mandibular Implant Failures. Proceedings of IPRASAP.( Oct ) Tokyo, Japan

Tang, YB. (2009). Mandibular Reconstructions, Selection of Method according to the Ultimate Results. Proceedings of the 5th Congress of the World Society for Reconstructive Microsurgery.(1/10-13 ) Hawaii, USA 
Tang, YB. (2009). The Fate of Different Reconstructive Modes for Mandibular Ameloblastomas. Proceedings of American Society for Reconstructive Microsurgery 2009 Annual Meeting. (1/10-13 ) Hawaii, USA.

Tang, YB.; Chen, HC. \& Hahn, LJ. (1994). Major Mandibular Reconstruction with Vascularized Bone Grafts-Indications and Selection of Donor Tissue, Microsurgery. Vol.15, p.227-237.

Taylor, GI. (1982). Reconstruction of the mandible with free composite iliac bone grafts. Ann Plast Surg Vol.9, p.361-76.

Taylor, GI. ; Townsend, P. \& Corlett, R. (1979). Superiority of the deep circumflex iliac vessels as the supply for free groin flaps. Plast Reconstr Surg Vol.64, p.745-59.

Wang, CH. ; Horng, SY. \& Tang, YB. (2002). Comparison of Vascularized Iliac and Fibular Bone Graft in Oromandibular Reconstruction. Proceedings of $18^{\text {th }}$ Annual meeting of Taiwan Surgical Association.(3/23-24 ) p.174

Yoshimura, M. ; Shimarrura, K. \& Yoshinobu, I. et al. (1983). Free vascularized fibular transplant, J Bone Joint Surg Ser A.. Vol., 65A, p.1295-301.

Yueh-Bih Tang*, C. H. Lee, and Y. M. Su. (2005) Aesthetic Facial Recontouring. Formosan Journal of Medicine Vol.2 No.9, p.214-222. 


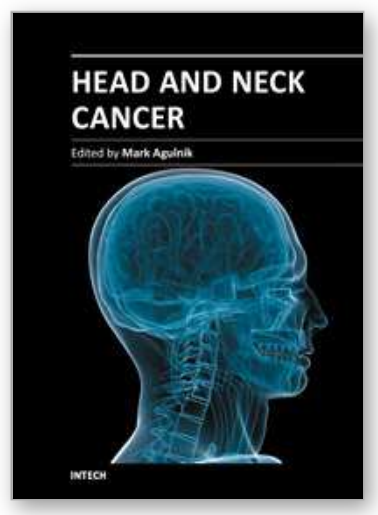

\author{
Head and Neck Cancer \\ Edited by Dr. Mark Agulnik
}

ISBN 978-953-51-0236-6

Hard cover, 440 pages

Publisher InTech

Published online 14, March, 2012

Published in print edition March, 2012

Head and Neck Cancer provides an interesting and comprehensive overview of all aspects of head and neck cancer including overviews of the disease, basic science aspects pertaining to the disease, diagnosis,

treatment and outcomes for patients with this disease. The chapters written by world renowned experts cover the entire discipline of head and neck oncology and include discussions of regional disparity is, advances in basic science understanding, advances in her radiotherapy, chemotherapy and targeted agents as well as a focus on reconstruction, prostheses, and aspects of quality of life and health outcomes. The book is designed to be both practical and comprehensive for every physician treating his complex disease.

\title{
How to reference
}

In order to correctly reference this scholarly work, feel free to copy and paste the following:

Yueh-Bih Tang Chen, Shih-Heng Chen and Hung-Chi Chen (2012). Finesse in Aesthetic Facial Recontouring, Head and Neck Cancer, Dr. Mark Agulnik (Ed.), ISBN: 978-953-51-0236-6, InTech, Available from: http://www.intechopen.com/books/head-and-neck-cancer/finesse-in-aesthetic-facial-recontouring-

\section{INTECH}

open science | open minds

\section{InTech Europe}

University Campus STeP Ri

Slavka Krautzeka 83/A

51000 Rijeka, Croatia

Phone: +385 (51) 770447

Fax: +385 (51) 686166

www.intechopen.com

\section{InTech China}

Unit 405, Office Block, Hotel Equatorial Shanghai

No.65, Yan An Road (West), Shanghai, 200040, China

中国上海市延安西路65号上海国际贵都大饭店办公楼 405 单元

Phone: +86-21-62489820

Fax: +86-21-62489821 
(C) 2012 The Author(s). Licensee IntechOpen. This is an open access article distributed under the terms of the Creative Commons Attribution 3.0 License, which permits unrestricted use, distribution, and reproduction in any medium, provided the original work is properly cited. 